methods of softening the effect of the light stimulation and of altering its colour. The best results were obtained by treating the outer glass with hydrofluoric acid and so rendering it translucent. The illumination of the standard and the translucent lights were measured by two independent observers by means of a Holophane lumeter, and it was found that the translucent light had an illumination 28 per cent. less than the standard lamp.

Thirty miners were tested for visual acuity with the standard and the translucent light by the method described by Flügel in the British Journal of Psychology, Vol. XI., 289. The results showed that with fifteen subjects visual acuity was better with the translucent light, with nine subjects visual acuity was equal with both lamps, and that with four subjects visual acuity was better with the standard lamp.

With nystagmic subjects the number and duration of aftersensations was more marked than with others, and tests showed that these subjects were those who appreciated the effects of the translucent light most.

The new lamp has found great favour with the miners, and is being supplied to them as fast as it can be manufactured.

The manager reports that "the men who have worked with the electric lamps fitted with opaque protecting glasses are very pleased with them, finding their work more comfortable, less strain on their eyes, and would not like to go back to the ordinary clear glasses again."

(A more detailed account of the experiments will be found in the Journal of the National Institute of Industrial Psychology, Vol. I., No. 5, and in the British Journal of Psychology, Vol. XIV., No. 1.)

\title{
THE VISION OF RAILWAY SERVANTS
}

BY

\author{
Sir James Barkett, K.B.E., C.M.G., \\ MELBOURNE, AUSTRALIA
}

THE interesting communication of Dr. Leonard Mitchell published in your. issue of July, 1922, on the Vision of Railway Men, raises quite a number of problems to which I should like to draw attention briefly.

1. The occasions to which he refers on which Dr. Orr, Dr. Murray and I tested the capacity of people with normal and supernormal vision to recognize signals in the open air showed conclusively that all such efforts are doomed to failure, if anything like accurate standardization is required. On these three occasions the distance at which the semaphore was recognized by people with normal 
vision varied enormously, as the subjoined reports show. We soon recognized that the distance at which the semaphore can be recognized depends on:-

1. The background, very materially.

2. The atmosphere, very materially.

3. The colour of the semaphore, to some extent.

We consequently decided to advise the Commissioner of Railways that open-air tests were certain to give trouble, that they were inaccurate, and that testing should be conducted indoors under standardized conditions.

2. A semaphore differs altogether from an ordinary test object, and if, as Dr. Mitchell says, it subtends an angle of five minutes at the given distance, it is certain that anyone with normal vision could see it much further away provided that the atmospheric conditions were good. It must, of course, be borne in mind also that with Snellen's types the details of the letters subtend an angle not of five minutes but of one minute. The arm of the semaphore, in the instance given by Dr. Mitchell, subtends an angle of five minutes lengthways and one minute in the other diameter; but a semaphore cannot be regarded as an ordinary test object, since it is really an opaque object on a light ground when the semaphore is properly placed.

3. The secondary colour defect, due to lowered visual acuity, of course simply reduces the distance at which coloured light can be recognized at night. Sir William Abney's well-known reference to the fixation of a standard of $6 / 12$ for mariners was because he found that ships' lights could be recognized by people with $6 / 12$ vision at a sufficient distance to ensure safety under ordinary conditions. Railway lights are not the same as ships' lights, and different considerations must apply.

4. If men are to be admitted to a Railway Service with vision of $6 / 12$ in each eye, there must be some ascertainable reason for the defect (usually refractive). As such men get older their vision is almost certain to deteriorate. In other words, they would be starting at the margin of safety.

5. The visual standards adopted in the Pilot Service of Victoria seem to me to be quite satisfactory, both from the point of view of safety, and of justice to the employee. The men entering the service must possess $6 / 6$ vision in each eye, and have a total error of refraction not exceeding one dioptre of which 0.5 dioptre may be astigmatic. They may not be excluded from the service so long as they possess vision of $6 / 12$ fully in each eye, that is practically $6 / 9$ with the two together. They are in an occupation with defined duties, they have the benefit of the experience gained from their work, and they possess at least the minimal standard which Sir William Abney regarded as just sufficent. 
The Report which follows is that to which Dr. Mitchell replies.

Report

\section{Resbecting the Examination of Vision for a Semaphore on the Werribee Line, Sunday, February 12, 1898.}

The distance at which the arm of the semaphore could be seen by those possessing $6 / 6$ vision depended largely on the background. With a grey mountain background it could be seen distinctly at a distance of 2,000 yards on the day in question, but against the background of the Station House, that is, as seen from the line, it is doubtful whether it could be seen at 600 yards by anyone possessing 6/6 vision. Taking for the particular day in question 2,000 yards as the standard, we found that Dr. Murray, who has vision $6 / 9$ in one eye, was able to distinguish the signal with that eye at 1,300 yards, and Mr. Beck, with vision of rather more than $6 / 12$ in one eye, and perhaps a little under 6/12 in the other, was able to distinguish the signal at 1,000 and 800 yards respectively. The examination disclosed the utter impossibility of fixing a definite standard, since at the two previous examinations made by Dr. Orr and Dr. Murray on different days the maximum distance for persons with $6 / 6$ vision proved to be 1,300 and 950 respectively. One of these days was a smoky one, and the other dusty, and the varying distances-1,300 and 950 yards-show how impossible it is to give an absolute value to $6 / 6$ vision as tested by semaphores. In both the latter cases the semaphore was seen against the clear sky.

A practical test of the kind would have to be conducted with the same semaphore, on the same background, and the standard would. have to be fixed each day of the examination by taking some one out with the examinee who had vision $6 / 6$, and setting the standard for that particular day before testing. An open air test of the kind would therefore in all probability be valueless, and might be dangerous. If, however, it is the wish of the Department to have an actual test with a semaphore, it would be a very easy thing to construct one on a reduced scale, set it in the passage at my office (100 feet long), place it against a uniform background, and work out the scale. There is, however, no advantage in so doing since the result must be the same as that given with test types.

It came as a surprise to us, however, to find that on certain backgrounds, semaphores may be invisible until the driver is close on them. One of the drivers this morning informs one of us (J.W.B.) that on the Mordialloc Line, near Cheltenham, there is a semaphore with a background of trees, which, in his opinion, cannot be seen more than a quarter of a mile distant. Assuming that such a semaphore as that at Laverton can be seen against the Station House or similar background at 600 yards on a clear day (such as yesterday), it is obvious that on a smoky or misty day it might be 
visible only at 400 yards to a person with $6 / 6$ vision, that is, to anyone with $6 / 12$ vision at 200 yards or anyone with $6 / 9$ vision at 270 yards. There is no point in carrying the test any further, but we desire in concluding to recommend :-

1. The $6 / 6$ standard be adhered to for those concerned in the actual running of the train, guards, signalmen, drivers and firemen, whom we may, following the usual practice, call class $\mathrm{A}$.

2. For class $B$, that is, the remainder of the service, the standard already fixed provides for $6 / 12$ vision in the bad eye, and $6 / 6$ in the good; but it is a matter for your consideration whether spectacles might not be worn by class $\mathrm{B}$.

3. It is clearly desirable that the various semaphores should be elevated where it is possible against the sky-line, and that where that is impossible a suitable back-ground should in some way be provided. It is further desirable that they should be painted pure white throughout.

Summarising the results of the preceding tests-viz., on February 10th and February 12th. On February 10th, it was found that anyone possessing $6 / 6$ vision could accurately see the arm of the semaphore at 900 yards. With vision of $6 / 9$ that limit of visibility was reduced to 600 yards. On this occasion the atmosphere was smoky.

On February 12 the results varied somewhat owing to dust storms coming on at intervals; but, under the best circumstances, a man with $6 / 6$ vision could distinguish the arm of the semaphore at 1,300 yards, and with $6 / 9$ vision at 900 yards.

On both these occasions the background was uniform, but the conditions of the atmosphere varied.

\section{ANNOTATIONS}

\section{The Bowman Lecture, 1923}

After a personal appreciation of the invitation received by himself at Washington in 1922 to deliver the lecture, Dr. de Schweinitz paid tribute to the memory of Sir William Bowman, as well as to the Ophthalmological Society of the United Kingdom, of which he was the first President, and entered on his subject, premising that he was utilizing his own experience, and acknowledging his indebtedness to many colleagues in the U.S.A.

A very careful study of the anatomical relations of the pituitary body and adjacent structures opened the subject of the lecture. The practical part of this work had been carried out by Dr. J. Parsons Schaeffer, and the results were brought clearly before the meeting by the series of careful drawings which were exhibited, 